\title{
Analysis of Microstructure and Mechanical Properties of Bismuth-Doped SAC305 Lead-Free Solder Alloy at High Temperature
}

\author{
Umair Ali ${ }^{1}$, Hamza Khan ${ }^{2}$, Muhammad Aamir ${ }^{3, *} \mathbb{0}$, Khaled Giasin ${ }^{4}{ }^{\oplus}$, Numan Habib ${ }^{1}$ \\ and Muhammad Owais Awan ${ }^{1}$ (D) \\ 1 Department of Mechanical Engineering, CECOS University of Information Technology and \\ Emerging Sciences, Peshawar 25000, Pakistan; umair@cecos.edu.pk (U.A.); \\ numanhabib@cecos.edu.pk (N.H.); mowais@cecos.edu.pk (M.O.A.) \\ 2 Government Advanced Technical Training Centre, Technical Education and Vocational Training Authority, \\ KPK, Peshawar 25000, Pakistan; khanhamxa@gmail.com \\ 3 School of Engineering, Edith Cowan University, Joondalup, WA 6027, Australia \\ 4 School of Mechanical and Design Engineering, University of Portsmouth, Portsmouth PO1 3DJ, UK; \\ khaled.giasin@port.ac.uk \\ * Correspondence: m.aamir@ecu.edu.au
}

check for updates

Citation: Ali, U.; Khan, H.; Aamir, M.; Giasin, K.; Habib, N.; Owais Awan, M. Analysis of Microstructure and Mechanical Properties of Bismuth-Doped SAC305 Lead-Free Solder Alloy at High Temperature. Metals 2021, 11, 1077. https:// doi.org/10.3390/met11071077

Academic Editors: José Spinelli and Jan Vrestal

Received: 12 May 2021

Accepted: 3 July 2021

Published: 5 July 2021

Publisher's Note: MDPI stays neutral with regard to jurisdictional claims in published maps and institutional affiliations.

Copyright: (c) 2021 by the authors. Licensee MDPI, Basel, Switzerland. This article is an open access article distributed under the terms and conditions of the Creative Commons Attribution (CC BY) license (https:// creativecommons.org/licenses/by/ $4.0 /)$.

\begin{abstract}
SAC305 lead-free solder alloy is widely used in the electronic industry. However, the problems associated with the growth formation of intermetallic compounds need further research, especially at high temperatures. This study investigates the doping of Bismuth into SAC305 in the various compositions of 1,2, and $3 \mathrm{wt} . \%$. The microstructure in terms of intermetallic compound particles and mechanical properties was examined after thermal aging at temperatures of $100{ }^{\circ} \mathrm{C}$ and $200{ }^{\circ} \mathrm{C}$ for $60 \mathrm{~h}$. The microstructure examination was observed using scanning electron microscopy, and the chemical composition of each alloy was confirmed with an energy dispersive $\mathrm{X}$-ray. Tensile tests were performed to find the mechanical properties such as yield strength and ultimate tensile strength. The intermetallic compound's phase analysis was identified using X-ray diffraction, and differential scanning calorimetry was done to study the temperature curves for melting points. Results showed that the addition of Bismuth refined the microstructure by suppressing the growth of intermetallic compounds, which subsequently improved the mechanical properties. The thermal aging made the microstructure coarsen and degraded the mechanical properties. However, the most improved performance was observed with a Bismuth addition of $3 \mathrm{wt} . \%$ into SAC305. Furthermore, a decrease in the melting temperature was observed, especially at Bismuth compositions of $3 \mathrm{wt} . \%$.
\end{abstract}

Keywords: lead-free solder; bismuth; microstructure; mechanical properties; thermal aging

\section{Introduction}

Electronics has many applications in various fields, such as aerospace, automotive, etc. [1]. In electronic industries, solder is widely used to make mechanical bonds, physically join the electronic component to the substrate, and permit electrical signals through the solder joint [2]. Electronic solders that withstand high temperatures are crucial for highpower semiconductor packaging, usually when the electronic systems are exposed to the temperature range of $175-200{ }^{\circ} \mathrm{C}$ [3]. Therefore, there is a need to assess the properties of solder alloys for the reliability of solder joints at elevated temperatures [4]. Additionally, when an electronic device is under operation, solder joints undergo mechanical stresses and strains. These stresses are induced in solder joints due to the different coefficients of thermal expansion of electronic components and circuit board on which solder joint is made [5]. Solder joints are also responsible for keeping the electronic components intact, which means they must possess excellent mechanical and thermo-mechanical properties to support the components [6]. 
The commonly used solder alloy in electronic manufacturing was the tin-lead (Sn63wt.\%-Pb37wt.\%) because of its good wettability, low melting temperature, availability, etc. [7]. However, lead $(\mathrm{Pb})$ has been restricted for further use in electronic components due to the low electronics' recycling rate and the adverse impact of $\mathrm{Pb}$ on human health [8-10]. Therefore, researchers and several industry groups have developed various lead-free solders alloys to drift toward green electronics [11]. Studies have shown that the Tin-Silver-Copper (SAC) series is considered the most potential lead-free solder (LFS) alloy due to its excellent fatigue resistivity, acceptable melting temperature, wetting properties, and joint reliability [12]. Among all the SAC alloys, SAC305 is the most popular and acceptable lead-free soldering alloy [3]. However, further research is needed regarding the growth rate of intermetallic compounds' (IMCs) particles under high temperatures to improve the reliability of the solder joint [12]. In this regard, the doping of various elements has been done into the SAC alloys to refine the microstructure and improve its mechanical properties.

For instance, Sabri et al. [13] concluded that the addition of Aluminum (1.0, 1.5, and 2.0) wt.\% into SAC105 resulted in refinement of the microstructure by suppressing the growth of IMCs, which further improved the mechanical properties, such as yield strength (YS) and ultimate tensile strength (UTS). Sadiq et al. [14] reported that the addition of Lanthanum $(0.01,0.05,0.25$, and 0.5$) \mathrm{wt} . \%$ into the SAC305 significantly improved the YS and UTS due to the reduced IMCs' particle size and refined microstructure. Chuang et al. [15] reported that the addition of Titanium (Ti) up to $1.0 \mathrm{wt} . \%$ into Sn-3.5Ag-0.5Cu improved YS, UTS, and micro-hardness due to the refinement of the microstructure.

Previous studies have also shown that Bismuth (Bi) was considered a potential choice due to its increased strength, good wettability, lower melting temperature, and lower cost than other alloys [16]. The Bi addition into SAC alloys also resulted in the refined microstructure and improved the mechanical properties [17]. In a study by Matahir et al. [18], it was found that the addition of Bi improved the mechanical properties of the SAC alloys. However, it should be taken into account that, with the higher addition of $\mathrm{Bi}$, the solder joint may become more exposed to brittle fracture due to increased strength. Hirai et al. [19] concluded that the tensile strength of SAC305 increased by adding Bi, and the SAC305-3Bi showed the highest tensile strength. Olofinjana et al. [20] also studied the addition of various compositions of Bi into SAC alloy. However, the investigation on the microstructure and mechanical properties at high thermal aging temperature, which is essential for the reliability of solder joints, was missing.

Therefore, this study investigated the analysis of microstructure and mechanical properties at Bi-doped SAC305 lead-free solder alloy at high thermal exposure for the reliability of the solder joints. The melting behavior, microstructure examination in terms of IMCs, and mechanical properties of SAC305 after the doping of various compositions of Bismuth (1,2, and 3) wt.\% were done. Finally, a comparison was made among all the selected alloys at high thermal aging temperature.

\section{Materials and Methods}

In this study, Tin (Sn) $(18 \mu \mathrm{m})$, Silver (Ag) $(75 \mu \mathrm{m})$, Copper $(18 \mu \mathrm{m})$, and Bismuth (Bi) $(45 \mu \mathrm{m})$ in powdered form were obtained from Beijing metallurgy and materials technology Co. Ltd. (Beijing, China) with a purity level of $99.8 \%$. To get the desired compositions of alloys, the elements were weighed using a highly sensitive digital scale (KERN ALS 220-4, Balingen, Germany) and were then placed in a ball-milling apparatus to get a uniform mixture of powdered alloy, as shown in Table 1. 
Table 1. Alloy composition.

\begin{tabular}{cccccc}
\hline \multirow{2}{*}{ S. No. } & Alloy Names & \multicolumn{5}{c}{ Wt.\% } \\
\cline { 3 - 6 } & & Sn & Ag & Cu & Bi \\
\hline 1 & SAC305 & 96.5 & 3.0 & 0.5 & 0 \\
2 & SAC305-1Bi & 95.5 & 3.0 & 0.5 & 1 \\
3 & SAC305-2Bi & 94.5 & 3.0 & 0.5 & 2 \\
4 & SAC305-3Bi & 93.5 & 3.0 & 0.5 & 3 \\
\hline
\end{tabular}

The mixed alloys in the powdered form were then placed in an alumina crucible, which was then placed in an electric furnace at a temperature of $1100{ }^{\circ} \mathrm{C}$ for $80 \mathrm{~min}$. The molten alloy obtained after heating was then poured into a specially designed casting die, which was preheated at $250{ }^{\circ} \mathrm{C}$ for $40 \mathrm{~min}$ to prevent casting defects and get a uniformly tensile specimen. The cooling of the molten alloy was carried out using air-cooling through fins of the die, and rapid cooling was avoided to mitigate any residual stresses in the tensile specimens. A Twin Prep $3^{\mathrm{TM}}$ Grinding/Polishing Machine (25-500 rpm, Allied High Tech Products, Inc., Rancho Dominguez, CA, USA) with a rotating abrasive disc and metallurgical silicon carbide sandpapers in grit size of 1200 was used for the polishing process. During this process, tap water was used for lubrication to avoid damage to the surface when the heat was generated. Finally, the specimens were cleaned with distilled water to remove any residue left during polishing. It is worth noting that the specimens were cut into small pieces and mounted in Bakelite for easy handling and to avoid any distortion during the polishing process.

The specimens were then placed in a drying oven (Thomas Scientific Model 605 with a maximum temperature of $300^{\circ} \mathrm{C}$, Swedesboro, NJ, USA) at thermally aged temperatures of $100{ }^{\circ} \mathrm{C}$ and $200{ }^{\circ} \mathrm{C}$ for $60 \mathrm{~h}$. Thermal aging is responsible for reducing strength due to a microstructure change after prolonged exposure to the material at elevated temperatures. The specimens were then etched using a Nital solution (comprising 90\% ethanol 10\% Nitric acid) for $30 \mathrm{~s}$ at room temperature. A scanning electron microscope (JSM5910, JEOL, Tokyo, Japan) was used to capture micrographs at various locations and different magnifications to examine the microstructure. At the same time, the validation of the chemical composition was performed using energy-dispersive X-ray spectroscopy (EDS) through INCA-200 Oxford Instruments, UK. The specimens were also analyzed to determine the IMCs' phases through XRD analysis (JDX-3532, JEOL, Tokyo, Japan). To further investigate the IMCs' particle sizes, the scanning electron microscope (SEM) images were digitally processed using ImageJ software (1.52i, NIH, Bethesda, MD, USA). First, the SEM images were uploaded in the ImageJ software and converted to 8- or 16-bit type. Then, a line was drawn equal to the existing scale bar on the original SEM images. Next, the scale on set scale command was adjusted as $\mu \mathrm{m}$ to follow the same unit displayed on the SEM images. After the scale setting, the threshold adjustment of the images was made to allow the software to variate the object of interest. Finally, the "analyze particles" command was used in the analyze menu of the software and that gave the required average particle size in $\mu \mathrm{m}$.

The behavior of as-casted and thermally aged specimens at different temperatures was analyzed using a universal testing machine (C224-E057B, Shimadzu, Kyoto, Japan) to determine the mechanical properties such as yield strength and ultimate tensile strength. Differential scanning calorimetry (DSC-8000 Perkin Elmer, Waltham, MA, USA) analysis was performed to determine the melting temperature of the alloy. The heating rate of the process was kept at $10{ }^{\circ} \mathrm{C} / \mathrm{min}$ while the procedure was carried out inside an argon inert environment with a heating range from $25^{\circ} \mathrm{C}$ to $260^{\circ} \mathrm{C}$ at a constant heating rate.

\section{Results and Discussion}

\subsection{Differential Scanning Calorimetry}

The melting temperature of solder alloys is crucial in the soldering process for enhancing the reliability and suppressing the thermal degradation of solders [21]. Figure 1 shows 
the differential scanning calorimetry (DSC) curves of un-doped and Bi-doped SAC305 alloy. It was found that each alloy showed a single peak in the DSC observation. The DSC analysis showed that the addition of $1 \mathrm{wt} . \%$ of Bi to SAC305 did not show a significant difference in the melting temperature; however, as the Bi concentration in SAC305 increased, the melting temperature decreased. The lowest melting temperature of $223.4^{\circ} \mathrm{C}$ was obtained at SAC305-3Bi with a drop of $6.8^{\circ} \mathrm{C}$ from SAC305, which has a melting temperature of $230.2{ }^{\circ} \mathrm{C}$.

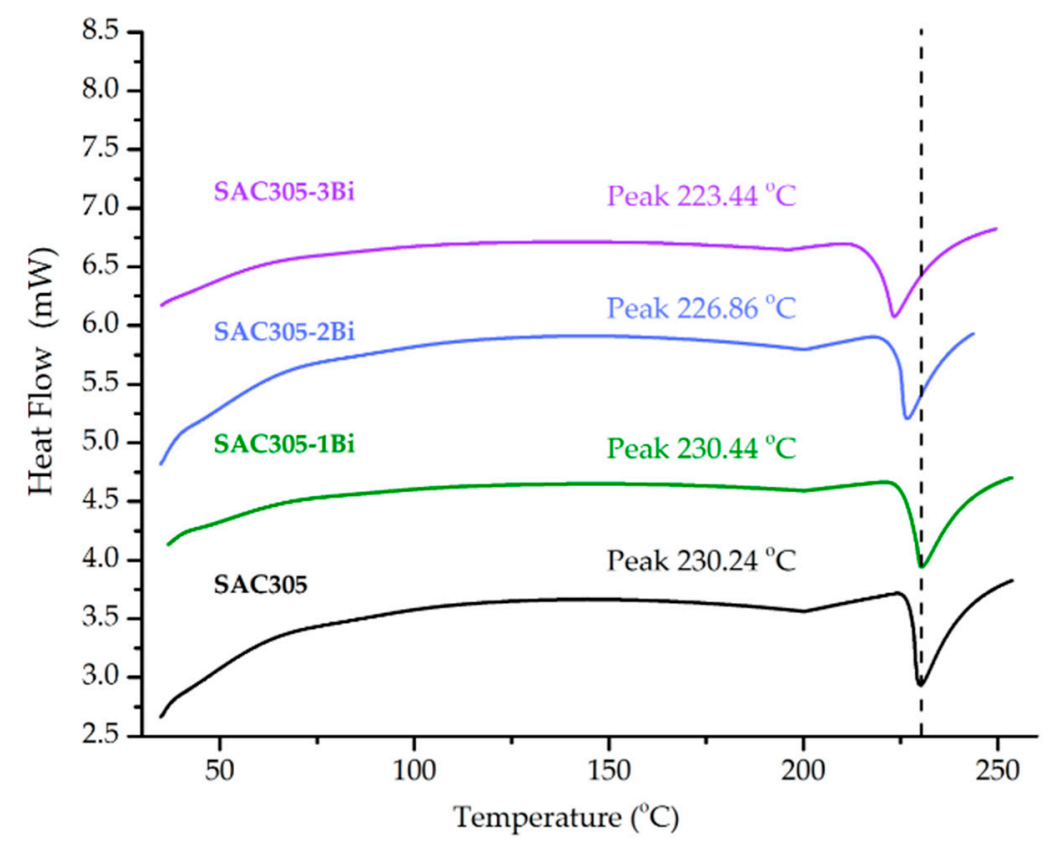

Figure 1. DSC curves for SAC305 with various Bi doping.

\subsection{X-ray Diffractions Analysis}

Figure 2 shows the $\mathrm{X}$-ray diffractions (XRD) of the SAC305 and SAC305-Bi to identify the IMC phases of $\mathrm{Ag}_{3} \mathrm{Sn}_{,} \mathrm{Cu}_{6} \mathrm{Sn}_{5}$, and the Bi. The results revealed the presence of $\mathrm{Ag}, \mathrm{Cu}$, and Sn IMCs in the form of $\mathrm{Ag}_{3} \mathrm{Sn}, \mathrm{Cu}_{6} \mathrm{Sn}_{5}$, and the $\mathrm{Sn}$ matrix, similar to the previous study by Yasmin et al. [3] where the type of IMCs' phases was identified using XRD; however, the doping element in SAC305 was Lanthanum. Fawzy et al. [22] also reported three types of phases: $\mathrm{Sn}, \mathrm{Ag}_{3} \mathrm{Sn}$, and $\mathrm{Cu}_{6} \mathrm{Sn}_{5}$ in the XRD investigation of SAC355 solder. The presence of $\mathrm{Ag}_{3} \mathrm{Sn}$ and $\mathrm{Cu}_{6} \mathrm{Sn}_{5}$ was due to the phase formation with eutectic $\mathrm{Sn}$ regions at the interfaces of the grains [23]. However, it is worth noting that Bismuth (Bi) did not show any IMC phase with other elements. Instead, it was observed as scattered over the solder alloy in the form of solid particulates $[17,19]$. 

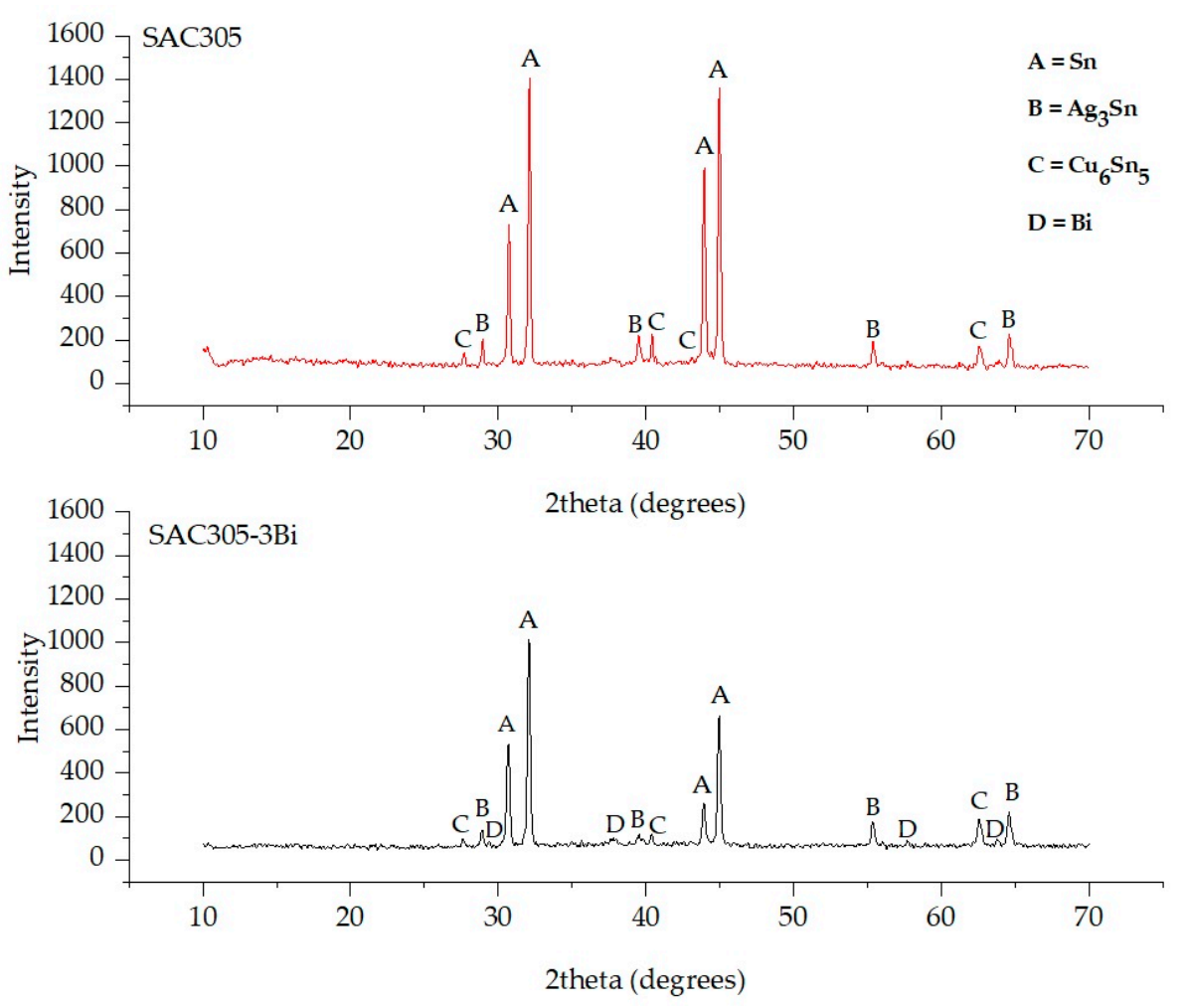

Figure 2. XRD analysis.

\subsection{Microstructure Examination and Analysis of Intermetallic Compound Particle Size}

Figure 3 shows the microstructural analysis of the SAC305 and Bi-doped SAC305 alloys and their verification of chemical composition by EDS is given in Figure 4. The results showed the presence of $\mathrm{Ag}_{3} \mathrm{Sn}$ and $\mathrm{Cu}_{6} \mathrm{Sn}_{5} \mathrm{IMCs}$, which were scattered over the Sn matrix [8]. The darker region shows the Sn-matrix and the eutectic area, the grey region indicates the presence of $\mathrm{Sn}-\mathrm{Cu}$, and the brighter regions along the grain colonies show the Sn-Ag IMCs. In contrast, the particles in the form of white or medium bright appearance show Bi particles. SEM micrographs also show that the microstructure became refined with the addition of $\mathrm{Bi}$. Bi was found in solid particles in the Sn-matrix without making any IMCs, resulting in refined microstructure, similar to the previous study by Hirai et al., 2019 [19], where the Bi particles were also present as solid-solved in the matrix. Therefore, Bi particles were found at the edges of the Sn-matrix and inter-dendritic regions, which provided a barrier for the dislocation movements and pinned grain boundaries that improved the mechanical properties [24]. According to Muhammad and Ali [25], the decrease in the IMCs' particle size resulted in the refinement of the microstructure and increased mechanical properties.

Figures 5 and 6 show the SEM micrographs of thermally aged specimens. The results showed that the dispersion of IMCs from the grain colonies caused the coarsening of the microstructure after thermal aging [26]. The $\mathrm{Cu}_{6} \mathrm{Sn}_{5}$ particles transformed to a whiskered, round shape from the granular form and become larger than the IMCs of $\mathrm{Ag}_{3} \mathrm{Sn}$ while being confined in the dendritic colonies [27]. In contrast, the microstructure of $\mathrm{Bi}$ at $3 \mathrm{wt} . \%$ showed IMCs' growth with suppressed and less scattered grain boundaries compared with un-doped SAC305 alloy and Bi-doped with 1 and $2 \mathrm{wt} . \%$, respectively. The dispersed Bi particles in the form of the solid solution provided anchorage to prevent the movement of fracture-dislocation regions [19]. Therefore, the microstructure of Bi-added SAC305 remained refined compared to un-doped SAC305 even after the thermal aging at high temperatures. 


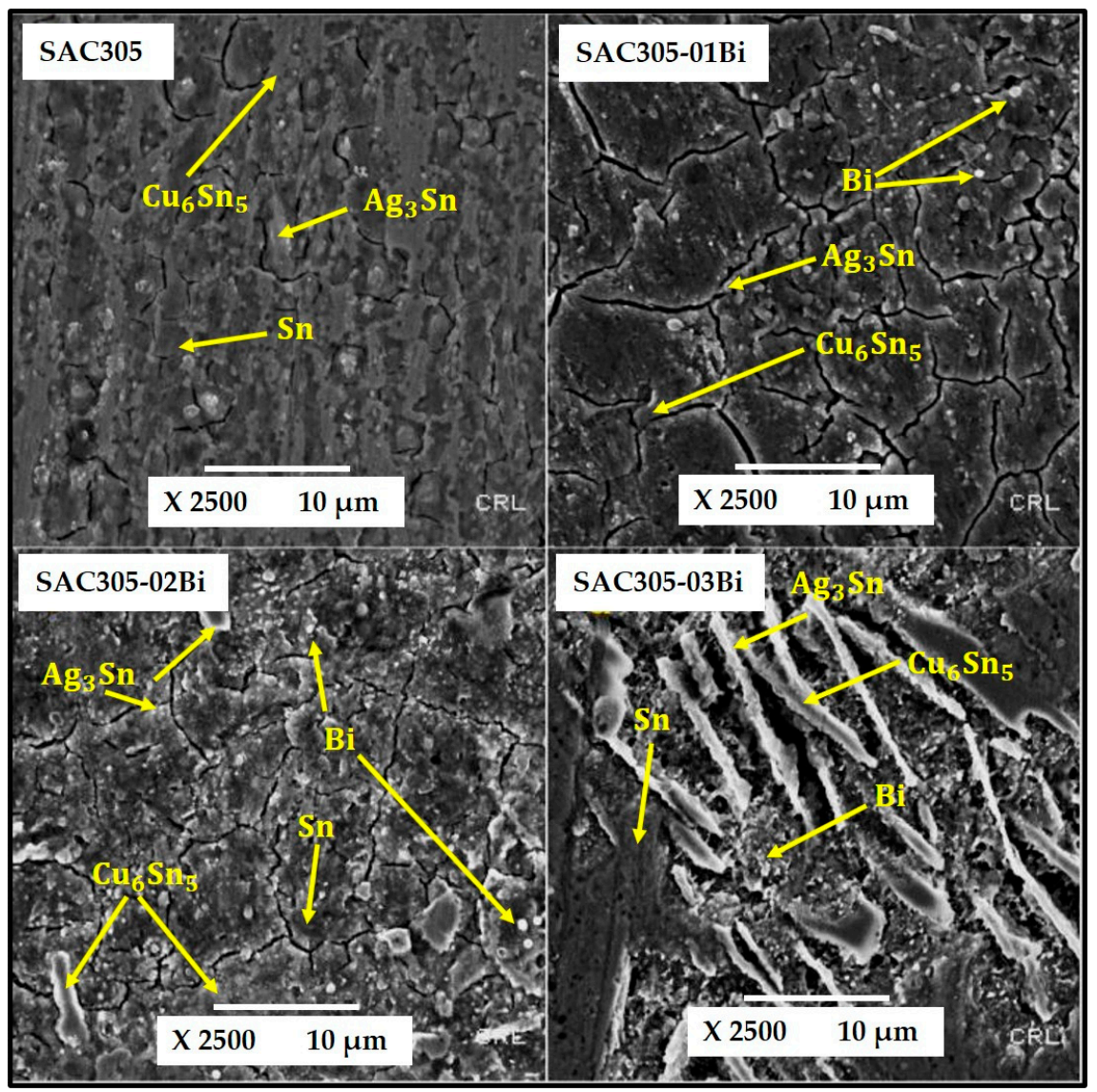

Figure 3. SEM of as-casted alloys.
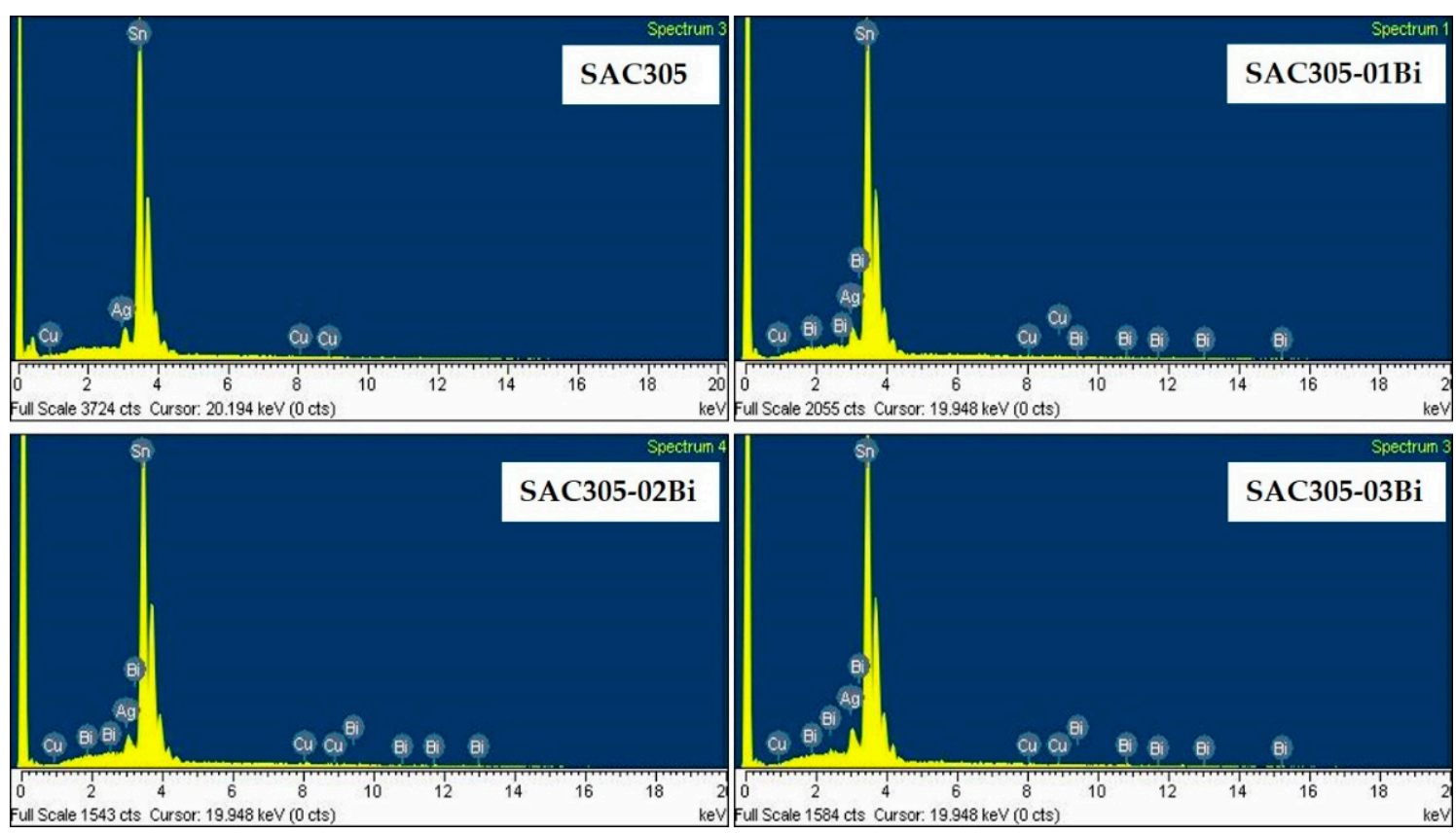

Figure 4. EDS of as-casted alloys. 


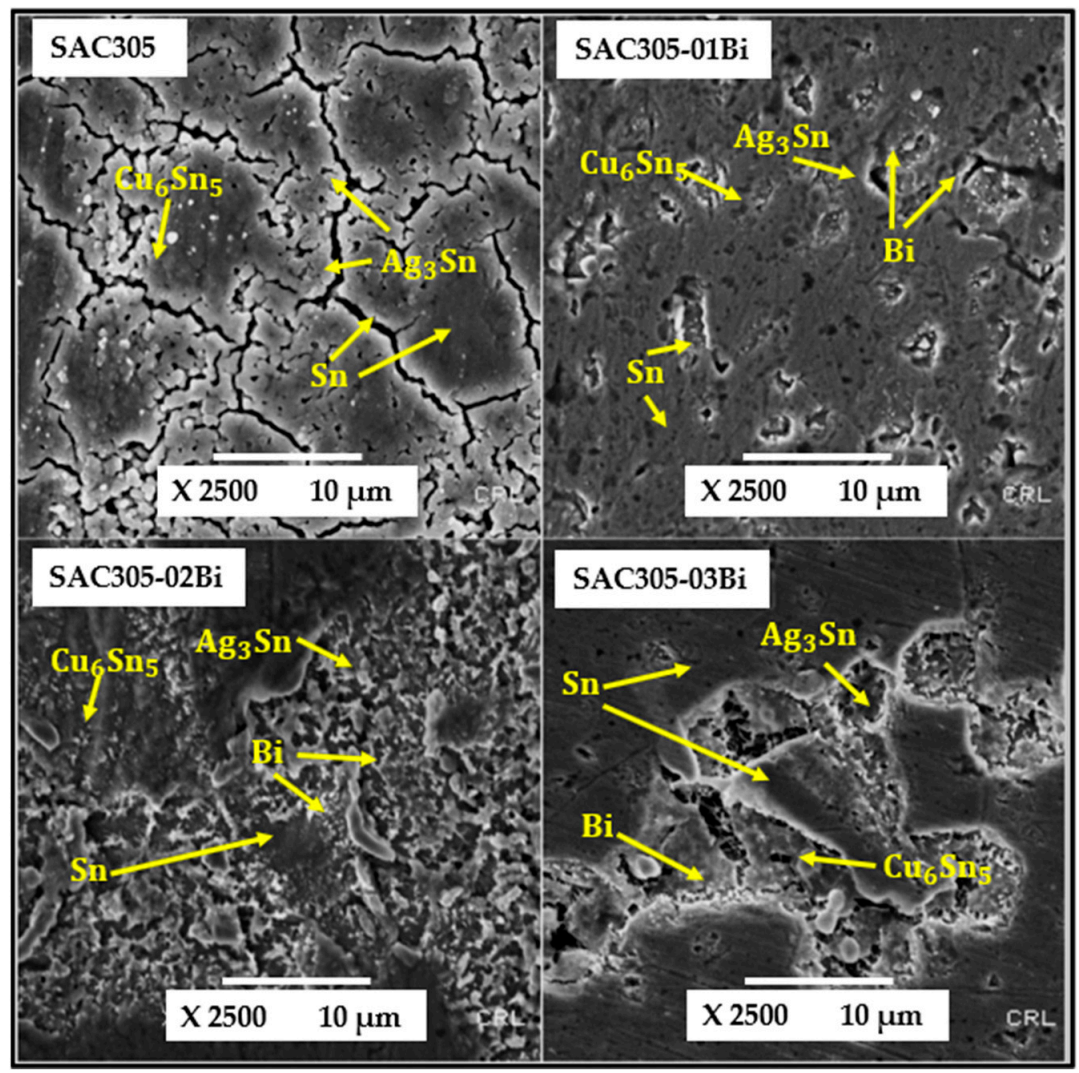

Figure 5. SEM images of thermally aged alloys at $100^{\circ} \mathrm{C}$.

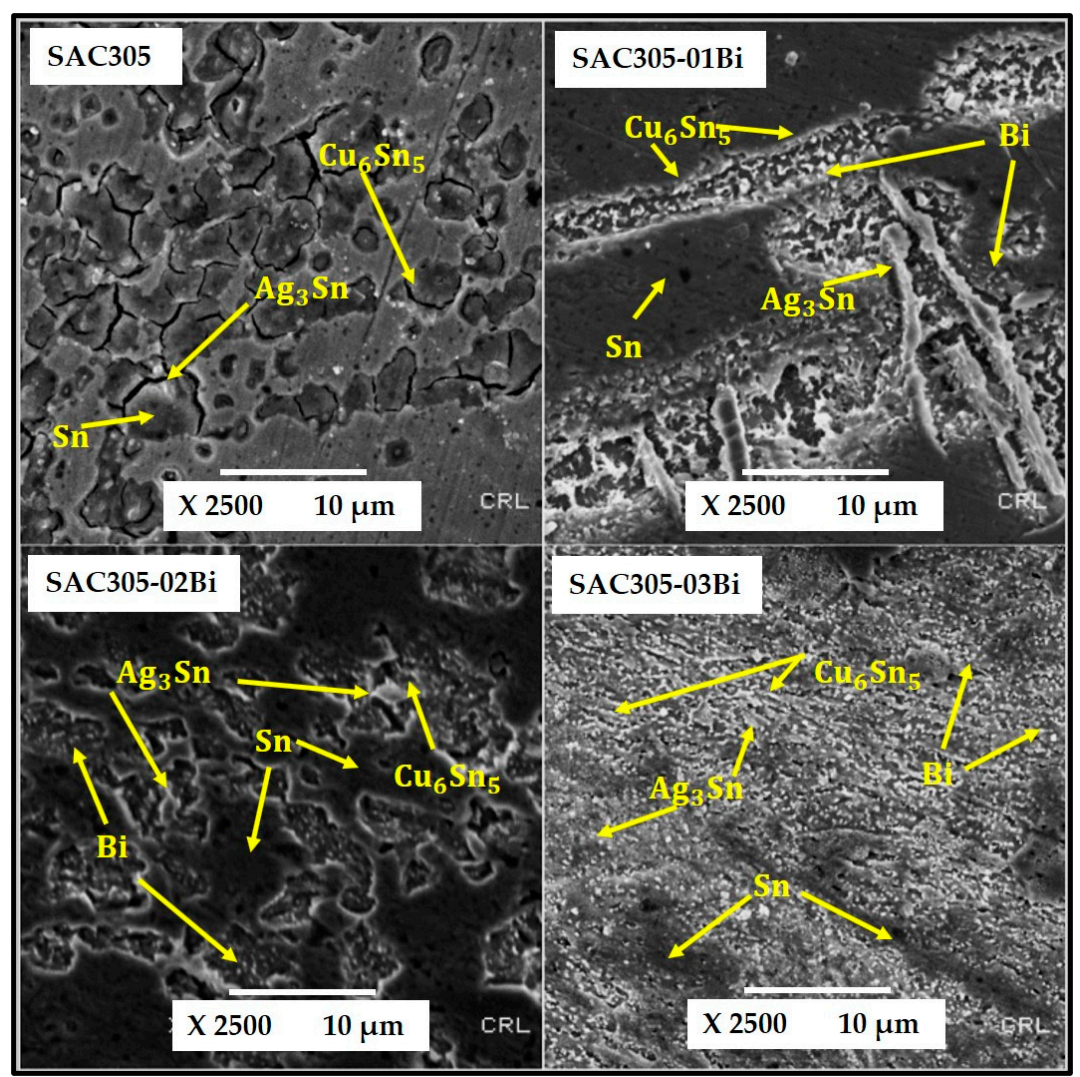

Figure 6. SEM images of thermally aged alloys at $200{ }^{\circ} \mathrm{C}$. 
To further analyze the microstructure of the specimens, the SEM micrographs were digitally analyzed using ImageJ software, similar to the previous studies [14,28], as shown in Figure 7. The average IMCs' particle size with 5\% error for the un-doped and Bidoped SAC305 alloy at different thermally aged temperatures is shown in Figure 8. The results showed that the addition of Bi into SAC305 reduced the IMCs' particle size, thus causing the grain boundaries to restrain from further growth and resulted in the refined microstructure [16]. On the other side, the thermal aging at $100{ }^{\circ} \mathrm{C}$ and $200{ }^{\circ} \mathrm{C}$ affected the microstructure by increasing the average IMCs' particle size. However, the microstructure of Bi-added SAC305 was less affected, as even after thermal aging, the IMCs' size was found to be less than SAC305.

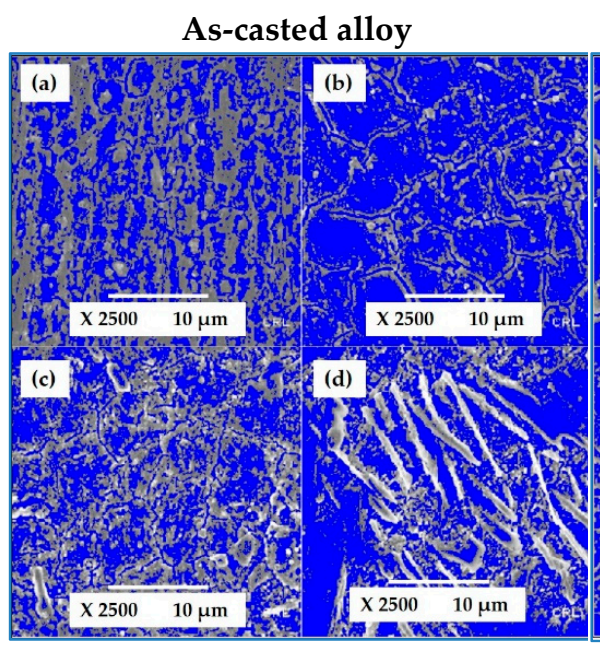

Thermally aged at $100^{\circ} \mathrm{C}$

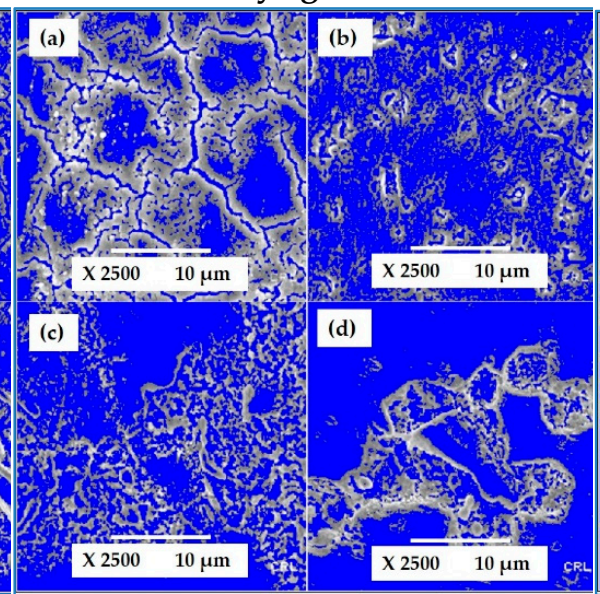

Thermally aged at $200^{\circ} \mathrm{C}$

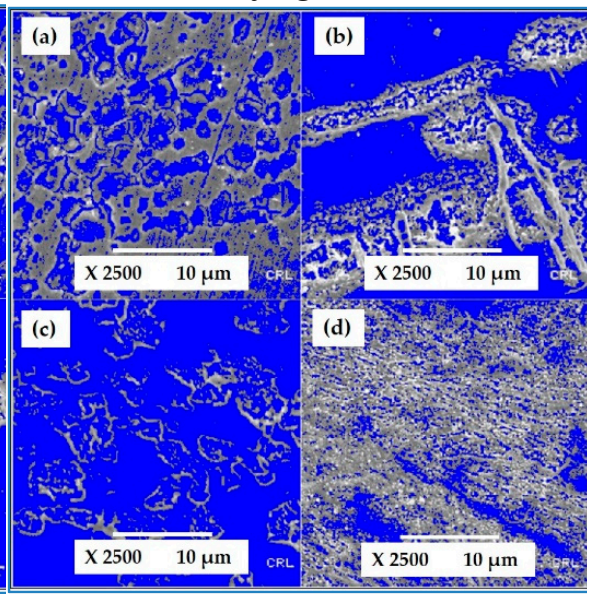

Figure 7. SEM images analyzed in ImageJ: (a) SAC305, (b) SAC305-1Bi, (c) SAC305-2Bi, (d) SAC305-3Bi.

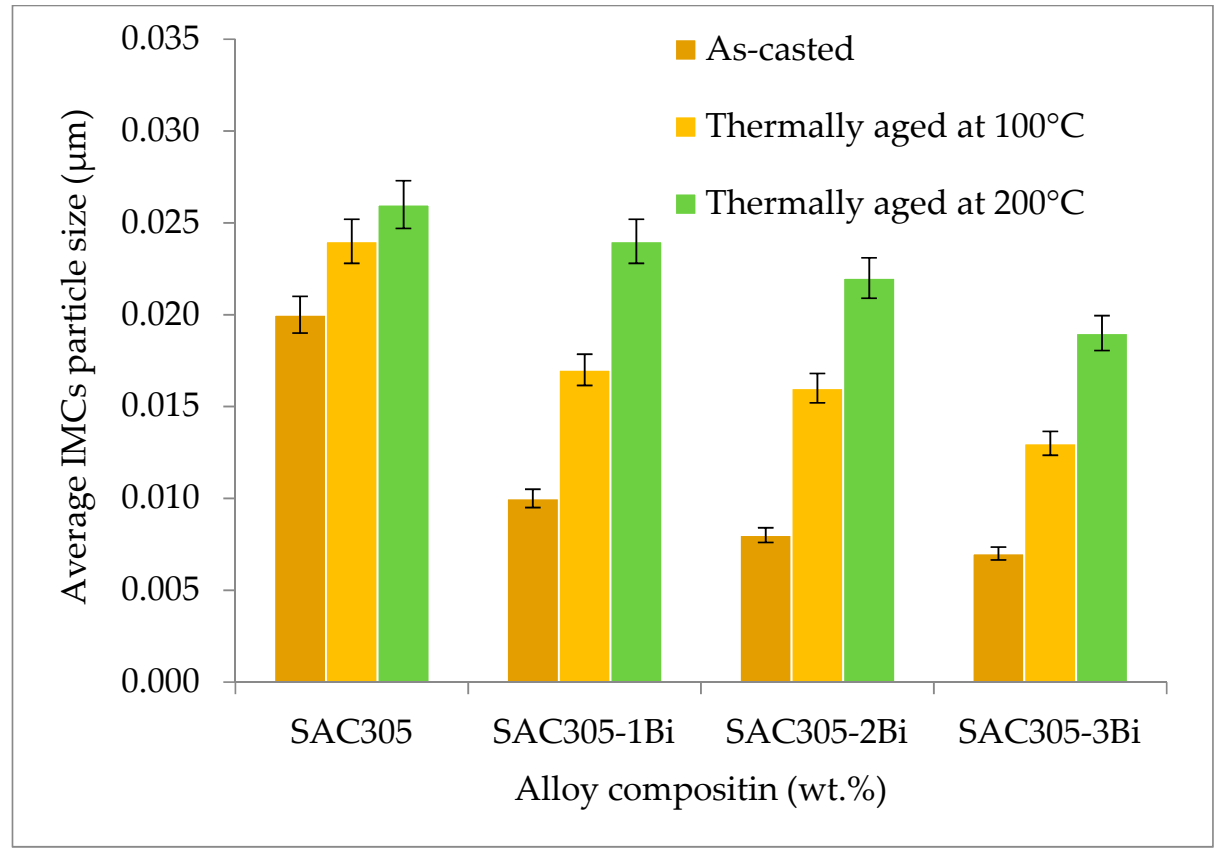

Figure 8. Average IMCs' particle size with alloy composition.

\subsection{Mechanical Properties}

Figures 9-11 show the results from the tensile tests for the un-doped and Bi-doped SAC305 alloys as a function of different aging temperatures. The results showed an increase in mechanical properties such as yield strength (YS) and ultimate tensile strength (UTS) 
after the Bi addition to SAC305. The highest improvement in the mechanical properties was investigated at $3 \mathrm{wt} . \%$ of Bi composition. The doping of $1 \mathrm{wt} . \%$ of Bi into SAC305 increased the YS up to $55 \mathrm{MPa}$, which was $39.1 \mathrm{MPa}$ for SAC305. The value of YS further increased to 72.5 and $83.4 \mathrm{MPa}$ for $2 \mathrm{wt} . \%$ and $3 \mathrm{wt} . \%$ of Bi addition, respectively. Similarly, the UTS for SAC305 was $46 \mathrm{MPa}$, which was increased up to 58.5, 77.6, and 96.7 MPa for SAC305-1Bi, SAC305-2Bi, and SAC305-3Bi, respectively. A likely explanation for the improvement in the SAC305 after the Bi doping could be the refinement of the microstructure due to the reduction in IMCs' particle size. The addition of $3 \mathrm{wt} . \%$ induced a higher dispersion of Bi particles over the eutectic region with the Sn matrix, which contributed to the enhancement of YS and UTS, as evident from the SEM images.

Figures 9-11 also show that, as the aging temperature increases from $100{ }^{\circ} \mathrm{C}$ and $200{ }^{\circ} \mathrm{C}$, a reduction in both YS and UTS was observed, which means that the microstructure of the thermally aged specimens at the high temperature was highly affected due to the IMCs' growth and subsequently reduced the solder joint reliability. Although the decrease in the mechanical properties was encountered while subjected to thermal aging, it is interesting to note that even after thermal aging at high temperatures, the mechanical properties of Bi-doped specimens were higher than the un-doped and aged SAC305.

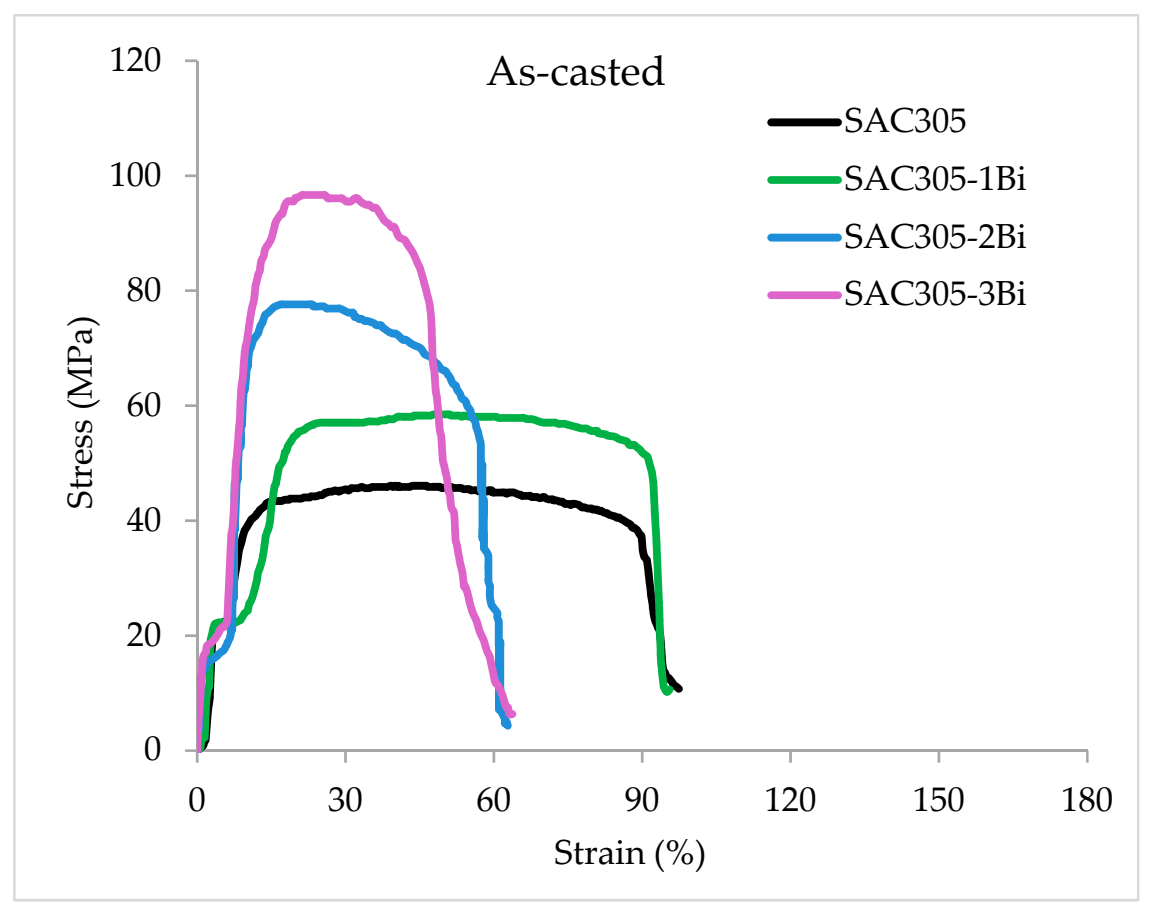

Figure 9. Stress-strain curves of thermally aged as-casted alloys. 


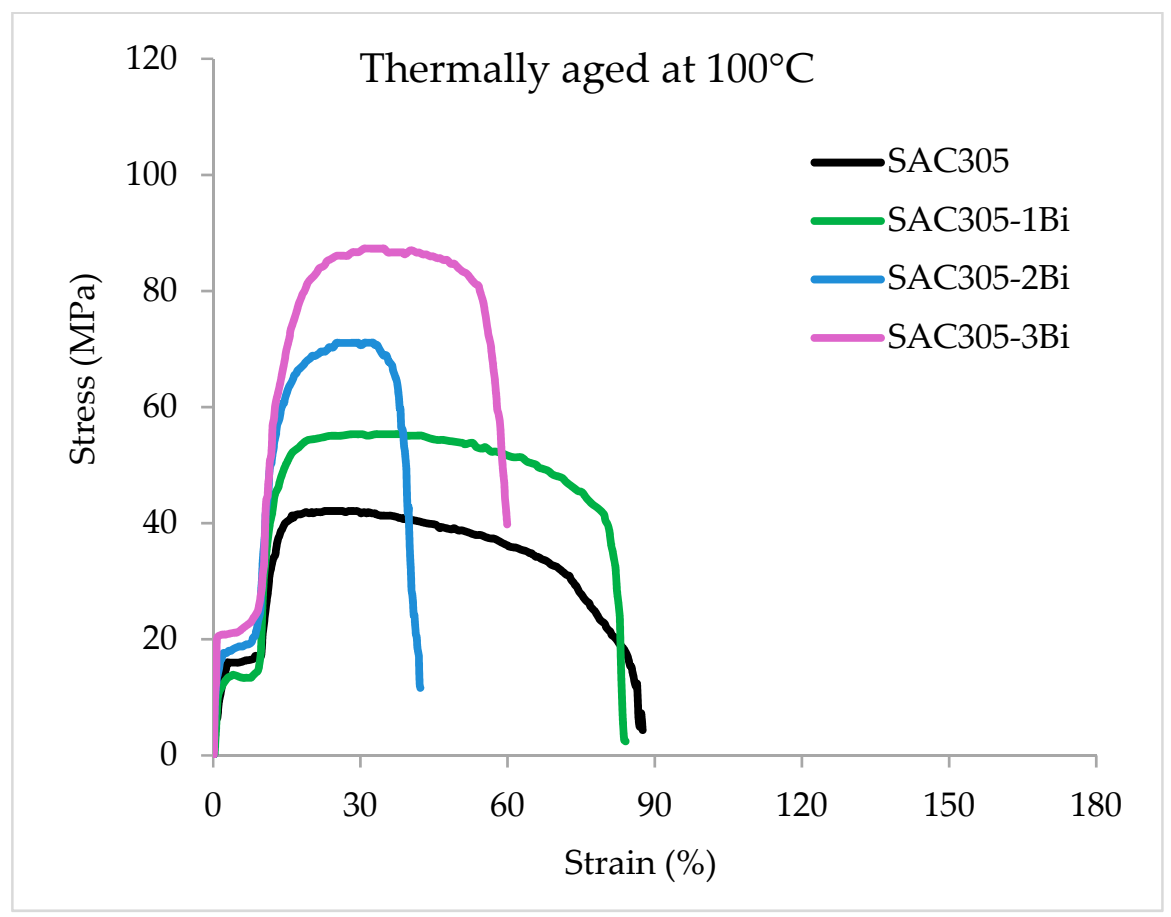

Figure 10. Stress-strain curves of thermally aged alloys at $100{ }^{\circ} \mathrm{C}$.

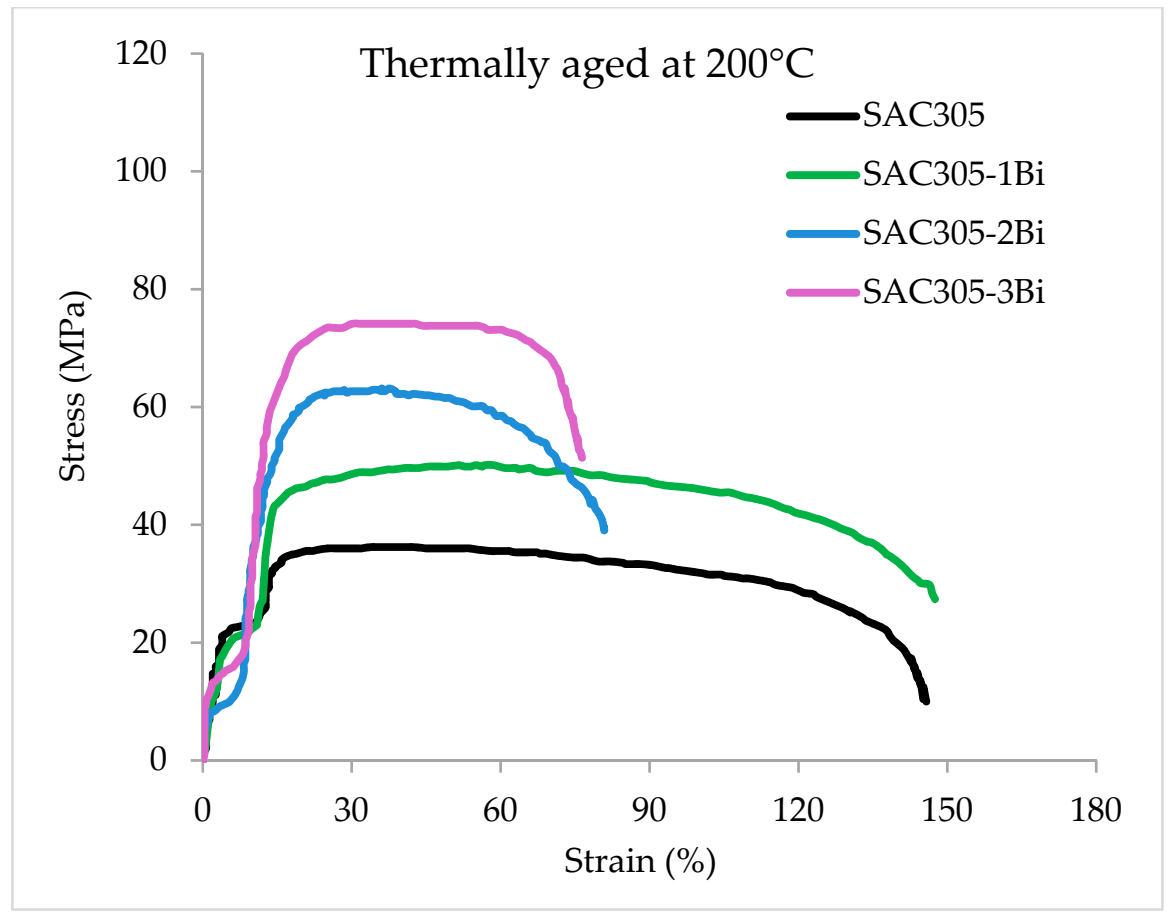

Figure 11. Stress-strain curves of thermally aged alloys at $200^{\circ} \mathrm{C}$.

\section{Conclusions}

In this study, the effects of Bismuth addition on the melting temperature, microstructure in terms of intermetallic compounds, and mechanical properties of SAC305 solder alloy were investigated under high-temperature aging. Differential scanning calorimetry analysis showed that the melting temperature reduced with the addition of Bismuth, and the lowest melting temperature was observed in the SAC305-3Bi. The intermetallic compound's grain boundaries became thin and less segregated because the scattered particles 
of Bismuth restricted the growth of intermetallic compound particle sizes such as $\mathrm{Ag}_{3} \mathrm{Sn}$ and $\mathrm{Cu}_{6} \mathrm{Sn}_{5}$, thus resulting in the refined microstructure. This, in return, enhanced the mechanical properties like yield strength and ultimate tensile strength of the solder alloy. On the other hand, the increase in the thermal aging temperature affected the microstructure and degraded the mechanical properties. However, it is worth noting that even after thermal aging at high temperatures, SAC305-3Bi was found to be the most favorable among the selected Bismuth compositions by giving the refined microstructure and improved mechanical properties.

Author Contributions: Conceptualization, U.A. and M.A.; methodology, U.A., M.A. and M.O.A.; validation, U.A., M.A., K.G. and M.O.A.; investigation, U.A., H.K., M.O.A. and N.H.; writingoriginal draft preparation, M.A., U.A., H.K., M.O.A. and N.H; writing-review and editing, M.A., U.A. and K.G. Authorship must be limited to those who have contributed substantially to the work reported. All authors have read and agreed to the published version of the manuscript.

Funding: This research received no external funding.

Institutional Review Board Statement: Not applicable.

Informed Consent Statement: Not applicable.

Data Availability Statement: The data presented in this study are available on request.

Acknowledgments: The authors would like to thank, for the support and facilitation, the centralized resource laboratory and material research laboratory of the University of Peshawar, Pakistan.

Conflicts of Interest: The authors declare no conflict of interest.

\section{Nomenclature}

$\begin{array}{ll}\text { Bismuth } & \mathrm{Bi} \\ \text { Copper } & \mathrm{Cu} \\ \text { Cerium } & \mathrm{Ce} \\ \text { Energy Dispersive X-Ray Spectroscopy } & \text { EDS } \\ \text { Differential scanning calorimetry } & \text { DSC } \\ \text { Intermetallic compounds } & \text { IMCs } \\ \text { Lead } & \mathrm{Pb} \\ \text { Lead-free solder } & \text { LFS } \\ \text { Scanning electron microscopy } & \text { SEM } \\ \text { Silver } & \text { Ag } \\ \text { Tin } & \text { Sn } \\ \text { Tin-Silver-Copper } & \text { SAC } \\ \text { Ultimate tensile strength } & \text { UTS } \\ \text { Universal testing machine } & \text { UTM } \\ \text { X-ray diffraction } & \text { XRD } \\ \text { Yield strength } & \text { YS } \\ \text { SAC105 } & \text { Sn-1.0 wt.\%Ag-0.5 wt.\%Cu } \\ \text { SAC305 } & \text { Sn-3.0 wt.\%Ag-0.5wt.\%Cu }\end{array}$

\section{References}

1. Li, R.; Cong, S.; Mei, J.; Zhang, L.; Chen, Z.; Li, T.; Yuan, X. Interface evolution and mechanical properties of Sn-36Pb-2Ag solder joints under different aging conditions. J. Mater. Res. Technol. 2021, 10, 868-881. [CrossRef]

2. Aamir, M.; Tolouei-Rad, M.; Din Israr, U.; Giasin, K.; Vafadar, A. Performance of SAC305 and SAC305-0.4La lead free electronic solders at high temperature. Solder. Surf. Mt. Technol. 2019, 31, 250-260. [CrossRef]

3. Yasmin, T.; Sadiq, M.; Khan, M. Effect of Lanthanum Doping on the Microstructure Evolution and Intermetallic Compound (IMC) Growth during Thermal Aging of SAC305 Solder Alloy. J. Mater. Sci. Eng. 2014, 3, 1000141. [CrossRef]

4. Aamir, M.; Muhammad, R.; Ahmed, N.; Sadiq, M.; Waqas, M. Mechanical properties of lead free solder alloy for green electronics under high strain rate and thermal aging. J. Eng. Appl. Sci. 2017, 36, 115-124.

5. Depiver, J.a.; Mallik, S.; Harmanto, D. Solder joint failures under thermo-mechanical loading conditions-A review. Adv. Mater. Process. Technol. 2021, 7, 1-26. [CrossRef] 
6. Abdul Ameer Shnawah, D.; Faizul Bin Mohd Sabri, M.; Anjum Badruddin, I.; Said, S. A review on effect of minor alloying elements on thermal cycling and drop impact reliability of low-Ag Sn-Ag-Cu solder joints. Microelectron. Int. 2012, $29,47-57$. [CrossRef]

7. Zhao, M.; Zhang, L.; Liu, Z.-Q.; Xiong, M.-Y.; Sun, L. Structure and properties of Sn-Cu lead-free solders in electronics packaging. Sci. Technol. Adv. Mater. 2019, 20, 421-444. [CrossRef] [PubMed]

8. Aamir, M.; Muhammad, R.; Tolouei-Rad, M.; Giasin, K.; Silberschmidt Vadim, V. A review: Microstructure and properties of tin-silver-copper lead-free solder series for the applications of electronics. Solder. Surf. Mt. Technol. 2019, 32, 115-126. [CrossRef]

9. Aamir, M.; Muhammad, R.; Hanif, M.; Ahmed, N. Relationships between Microstructure and Mechanical Properties in High Sn Content Pb-based and Pb-Free Solder Alloy after Thermal Aging. Int. J. Adv. Mater. Manuf. 2016, 1, 33-41.

10. Aamir, M.; Muhammad, R.; Ahmed, N.; Alam, K. Impact of Thermal Aging on Microstructure and Mechanical Properties of high $\mathrm{Sn}$ Content, Sn-Pb Solders. In Proceedings of the Fourth International Conference on Aerospace Science \& Engineering, Islamabad, Pakistan, 2-4 September 2015; pp. 187-191.

11. Hashim, A.N.; Salleh, M.A.A.M.; Sandu, A.V.; Ramli, M.M.; Yee, K.C.; Mohd Mokhtar, N.Z.; Chaiprapa, J. Effect of Ni on the Suppression of Sn Whisker Formation in Sn-0.7Cu Solder Joint. Materials 2021, 14, 738. [CrossRef] [PubMed]

12. Aamir, M.; Muhammad, R.; Ahmed, N.; Waqas, M. Impact of thermal aging on the intermetallic compound particle size and mechanical properties of lead free solder for green electronics. Microelectron. Reliab. 2017, 78, 311-318. [CrossRef]

13. Sabri, M.F.M.; Shnawah, D.A.; Badruddin, I.A.; Said, S.B.M.; Che, F.X.; Ariga, T. Microstructural stability of Sn-1Ag-0.5 Cu-xAl $(\mathrm{x}=1,1.5$, and $2 \mathrm{wt} . \%)$ solder alloys and the effects of high-temperature aging on their mechanical properties. J Mater. Charact. 2013, 78, 129-143. [CrossRef]

14. Sadiq, M.; Pesci, R.; Cherkaoui, M. Impact of thermal aging on the microstructure evolution and mechanical properties of lanthanum-doped tin-silver-copper lead-free solders. J. Electron. Mater. 2013, 42, 492-501. [CrossRef]

15. Chuang, C.; Tsao, L.; Lin, H.; Feng, L. Effects of small amount of active Ti element additions on microstructure and property of Sn3. 5Ag0. 5Cu solder. Mater. Sci. Eng. A 2012, 558, 478-484. [CrossRef]

16. Ali, B.; Sabri, M.F.M.; Jauhari, I.; Sukiman, N.L. Impact toughness, hardness and shear strength of Fe and Bi added Sn-1Ag-0.5Cu lead-free solders. Microelectron. Reliab 2016, 63, 224-230. [CrossRef]

17. Erer, A.M.; Oguz, S.; Türen, Y. Influence of bismuth (Bi) addition on wetting characteristics of Sn-3Ag-0.5Cu solder alloy on Cu substrate. Eng. Sci. Technol. Int. J. 2018, 21, 1159-1163. [CrossRef]

18. Matahir, M.; Chin, L.; Tan, K.; Olofinjana, A. Mechanical strength and its variability in Bi-modified Sn-Ag-Cu solder alloy. J. Achiev. Mater. Manuf. Eng. 2011, 46, 50-56.

19. Hirai, Y.; Oomori, K.; Morofushi, H.; Shohji, I. Effect of Bi Addition on Tensile Properties of Sn-Ag-Cu Solder at Low Temperature. Mater. Trans. 2019, 60, 909-914. [CrossRef]

20. Olofinjana, A.; Haque, R.; Mathir, M.; Voo, N.Y. Studies of the solidification characteristics in Sn-Ag-Cu-Bi solder alloys. Procedia Manuf. 2019, 30, 596-603. [CrossRef]

21. El-Daly, A.; El-Taher, A.; Gouda, S. Development of new multicomponent Sn-Ag-Cu-Bi lead-free solders for low-cost commercial electronic assembly. J. Alloys Compd. 2015, 627, 268-275. [CrossRef]

22. Fawzy, A.; Fayek, S.; Sobhy, M.; Nassr, E.; Mousa, M.; Saad, G. Tensile creep characteristics of Sn-3.5 Ag-0.5 Cu (SAC355) solder reinforced with nano-metric ZnO particles. Mater. Sci. Eng. A 2014, 603, 1-10. [CrossRef]

23. Subri, N.W.B.; Sarraf, M.; Nasiri-Tabrizi, B.; Ali, B.; Mohd Sabri, M.F.; Basirun, W.J.; Sukiman, N.L. Corrosion insight of iron and bismuth added Sn-1Ag-0.5 Cu lead-free solder alloy. Corros. Eng. Sci. Technol. 2020, 55, 35-47. [CrossRef]

24. Mahdavifard, M.H.; Sabri, M.F.M.; Shnawah, D.A.; Said, S.M.; Badruddin, I.A.; Rozali, S. The effect of iron and bismuth addition on the microstructural, mechanical, and thermal properties of Sn-1Ag-0.5 Cu solder alloy. Microelectron. Reliab. 2015, 55, 1886-1890. [CrossRef]

25. Muhammad, R.; Ali, U. Optimized cerium addition for microstructure and mechanical properties of SAC305. Solder. Surf. Mt. Technol. 2020. ahead-of-print. [CrossRef]

26. Aamir, M.; Waqas, M.; Iqbal, M.; Hanif, M.I.; Muhammad, R. Fuzzy logic approach for investigation of microstructure and mechanical properties of Sn96.5-Ag3.0-Cu0.5 lead free solder alloy. Solder. Surf. Mt. Technol. 2017, 29, 191-198. [CrossRef]

27. Witkin, D.B. Influence of microstructure on quasi-static and dynamic mechanical properties of bismuth-containing lead-free solder alloys. Mater. Sci. Eng. A 2012, 532, 212-220. [CrossRef]

28. Ali, B. Advancement in microstructure and mechanical properties of lanthanum-doped tin-silver-copper lead free solders by optimizing the lanthanum doping concentration. Solder. Surf. Mt. Technol. 2015, 27, 69-75. [CrossRef] 